ORNL/TM-13676

\title{
Scouting Tests to Examine Potential Corrosion of Aluminum Alloy 2519 During Fabrication
}

\author{
S. J. Pawel
}

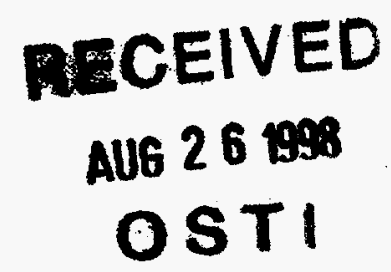

IIANAGED AND OPERATED BY

LOCKHEEO WARTIN ENERGY RESEARCH CORPOAATION FOR THE UNTEO STATES

DEPAPTIENT OF ENERGY 
This report has been reproduced directly from the best available copy.

Available to DOE and DOE contractors from the Office of Scientific and Technical Information, P.O. Box 62, Oak Ridge, TN 37831; prices available from (423)576-8401.

Available to the public from the National Technical Information Service, U.S. Department of Commerce, 5285 Port Royal Rd., Springfield, VA 22161.

This report was prepared as an account of work sponsored by an agency of the United States Government. Neither the United States Government nor any agency thereof, nor any of their employees, makes any warranty, express or implied, or assumes any legal liability or responsibility for the accuracy, completeness, or usefulness of any information, apparatus, product, or process disclosed, or represents that its use would not infringe privately owned rights. Reference herein to any specific commercial product, process, or service by trade name, trademark, manufacturer, or otherwise, does not necessarily constitute or imply its endorsement, recommendation, or favoring by the United States Government or any agency thereof. The views and opinions of authors expressed herein do not necessarily state or reflect: those of the United States Government or any agency thereof. 


\section{DISCLAIMER}

Portions of this document may be illegible in electronic image products. Images are produced from the best available original document. 
Metals and Ceramics Division

\title{
Scouting Tests to Examine Potential Corrosion of Aluminum Alloy 2519 During Fabrication
}

S. J. Pawel

Date Published: August 1998

\author{
Prepared for the \\ U.S. Department of Energy \\ Advanced Amphibious Assault Vehicle (AAAV) Program \\ 14 B2 50601 \\ Prepared by \\ OAK RIDGE NATIONAL LABORATORY \\ Oak Ridge, Tennessee 37831-6285 \\ managed by \\ LOCKHEED MARTIN ENERGY RESEARCH CORP. \\ for the \\ U.S. DEPARTMENT OF ENERGY \\ under contract DE-AC05-96OR22464
}





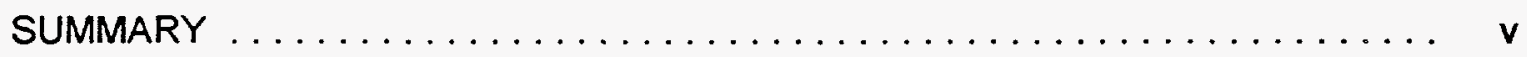

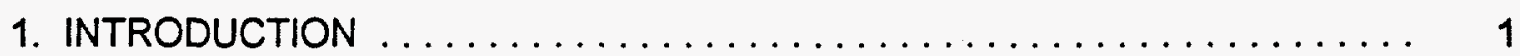

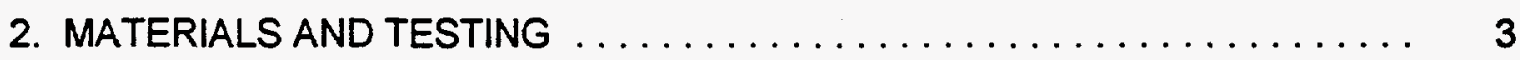

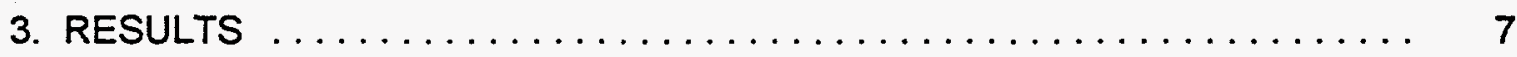

4. CONCLUSIONS AND RECOMMENDATIONS $\ldots \ldots \ldots \ldots \ldots \ldots \ldots \ldots, 11$

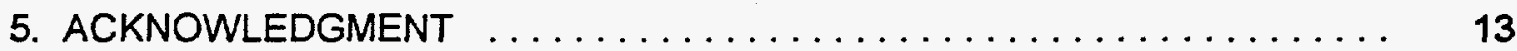




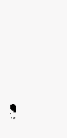




\section{SUMMARY}

Coupons of 2519 aluminum were exposed for three weeks in a variety of environments representative of those expected during fabrication of the advanced amphibious assault vehicle (AAAV). Specimens exposed to tap water developed very minor pitting and staining, while specimens exposed in high humidity air, water chaser, or machine cutting fluid revealed no detectable changes. 


.




\section{INTRODUCTION}

At the $Y-12$ facility, aluminum alloy 2519 will be subjected to routine handling associated with the fabrication process(es) for the advanced amphibious assault vehicle (AAAV). It is anticipated that the fabrication environment to which the 2519 aluminum will be exposed includes various combinations of

ambient, potentially high humidity, air;

a building tap water for rinsing;

a machine cutting fluid (exclusively "microsol 165");

a water chaser (exclusively "solvent 140"); and

a different metals from fixturing or work tables (primarily 6061 aluminum and/or mild steel).

A series of scouting test exposures were performed with coupons of 2519 aluminum in the above environments to determine whether special handling procedures need to be implemented during component fabrication. (The corrosion of 2519 aluminum under AAAV service conditions is outside the scope of this particular evaluation.) 
.

. 


\section{MATERIALS AND TESTING}

Material for test coupons was cut from one inch plates of 2519 aluminum in storage at the $Y-12$ facility for use in the AAAV program. Aluminum alloy 2519 , an Al-6\% Cu material (with small fractions of a percent of a few other elements), is commonly used for military armor plate. In this application, it is frequently utilized in the T87 temper condition. Neither the specific composition nor the heat treatment of the 2519 aluminum plate material used in this investigation was reported, but it is assumed to be prototypic of material that will be used for AAAV fabrication.

Because corrosion behavior is sometimes dependent on orientation relative to the plate rolling direction, coupons emphasizing two different major orientations were used in these scouting tests. One set of coupons was sized as $5.1 \mathrm{~cm}$ ( 2 in.) long by $2.5 \mathrm{~cm}$ ( 1 in.) wide by $0.64 \mathrm{~cm}(0.25$ in.) thick, with the largest surfaces representing the plate cross section. The other set of coupons was sized somewhat larger as $5.1 \mathrm{~cm}$ ( $2 \mathrm{in}$.) long by $2.5 \mathrm{~cm}$ ( $1 \mathrm{in}$.) wide by $2.5 \mathrm{~cm}$ ( 1 in.) thick, with the largest surfaces representing the rolling surface. The latter size generated a specimen with an area of $25.8 \mathrm{~cm}^{2}\left(4 \mathrm{in}^{2}\right)$ are in the rolling plane, compared to only $6.5 \mathrm{~cm}^{2}\left(1 \mathrm{in.}^{2}\right)$ of rolling plane surface in the other specimens). The total surface area for the small coupons was about $35 \mathrm{~cm}^{2}\left(5.5 \mathrm{in}^{2}\right)$ and about $64 \mathrm{~cm}^{2}$ (10 in. ${ }^{2}$ ) for the large specimens.

During the fabrication process, the 2519 aluminum is expected to be exposed to various fluids, including tap water, cutting fluid (a petroleum oil based product called "microsol 165"), and a water chaser (solvent 140). In these experiments, tap water from the fabrication building was used so that any potential contaminants in the water would be included in the tests. In addition, the microsol 165 used for these experiments was taken from the building supply of as-mixed and slightly used material as representative of that which would be used routinely during fabrication.

The fabrication process is not expected to involve extended immersion exposures, but a brief immersion followed by an extended "storage" period is within the realm of likelihood. This possibility is potentially corrosive to aluminum in that evaporation of these fluids could tend to concentrate any aggressive contaminants. Therefore, in addition to the static immersion exposures in "fabrication fluids," specimens were dipped in each fluid and subsequently stored in a high humidity 
environment. The latter specimens were laid flat - i.e., either the large rolling surface or large plate cross section was facing up, depending on coupon type - on small diameter alumina rods placed on the floor grate of the humidity chamber. A few drops of the test fluid were then placed on top of the coupons, and the chamber closed. The immersion specimens were exposed together in 1 liter beakers of the appropriate fluid, and the beaker was contained in a large zip-lock type of plastic bag to limit evaporation.

The high humidity environment was created chemically in the intemal volume of a large, closed desiccator. This was accomplished by placing approximately $500 \mathrm{~g}$ of potassium nitrate in the bottom of the container and adding just enough distilled water to fully saturate the resulting solution with a bare minimum of excess free liquid. (See ASTM Standard Practice E-104.) The temperature of the desiccator and contents remained at ambient room temperature $\left(20-22^{\circ} \mathrm{C}\right)$ for the duration of the exposure, corresponding to an equilibrium relative humidity $(\mathrm{RH})$ in the closed volume of about $94.5 \%$.

Various fixtures, clamps, and support surfaces in the fabrication shop are constructed of other aluminum alloys (mainly 6061 aluminum) or mild steel. As a result of contact between these surfaces and 2519 aluminum, corrosion associated with a galvanic couple between these materials is a possibility. To examine this potential concern, 2519 aluminum coupons were positioned on top of 6061 aluminum wetted with tap water or microsol 165 in the $95 \%$ RH chamber. In addition, 2519 aluminum was placed on "dry" (oxidized and lightly abraded) mild steel in the 95\% RH chamber.

Surface preparation for each as-received coupon of 2519 aluminum consisted of firmly wiping the surface with paper towels to remove as much residual cutting fluid and handling debris (metal shavings, finger grease, etc) as practical. In this way, the as-rolled surface and the as-cut surfaces (with serrations and disturbed metal) were left as "representative" of the fabrication surfaces as possible. The only exceptions to this pattern were the "control" specimens, which were cleaned ultrasonically in acetone for about a minute each prior to weighing and exposure.

In summary, duplicate specimens of each orientation were exposed (undisturbed) for $\mathbf{2 0}$ days in each of the following conditions: 
(a) ultrasonically cleaned in acetone, then exposed at $95 \% \mathrm{RH}$;

(b) dipped in microsol 165, then exposed at $95 \% \mathrm{RH}$;

(c) dipped in microsol 165 , dipped in solvent 140 , then exposed at $95 \% \mathrm{RH}$;

(d) dipped in microsol 165 , dipped in tap water, then exposed at $95 \% \mathrm{RH}$;

(e) immersed in microsol 165;

(f) immersed in tap water,

(g) immersed in solvent 140;

(h) galvanic couple with tap water, 2519 on 6061 in $95 \% \mathrm{RH}$;

(i) galvanic couple with microsol 165, 2519 on 6061 in $95 \% \mathrm{RH}$; and

(j) galvanic couple but no obvious free liquid, 2519 on mild steel in $95 \%$ RH. 


\section{RESULTS}

For the exposure conditions labeled (a), (b), (c), (d), (e), (g), (i), and (j), no change of any sort was macroscopically apparent on the coupons. No significant change in weight was observed for any of the coupons so exposed $(+/-0.0005$ grams on a surface area of at least $35 \mathrm{~cm}^{2}$ ). This result is consistent with open literature results for many aluminum alloys indicating very low general corrosion rates in water. For the weight changes associated with these environments, the corresponding general corrosion rates are all $<2 \mu \mathrm{m} / \mathrm{yr}(<0.1 \mathrm{mils} / \mathrm{yr})$. Further, no change in color/luster was observed nor were there any indications of pitting on the surfaces of the 2519 aluminum in the environments (a), (b), (c), (d), (e), (g), (i), and (j).

The only exposure conditions for which any sort of reaction was observed were those labeled $(f)$ and $(h)$ in the above list. These environments have in common a significant amount of tap water from the fabrication building. For the specimens immersed in tap water, very mild pitting was observed in limited areas. Specifically, at the end of the exposure period, one of the two "large" coupons immersed in tap water exhibited shallow scattered pitting over an area of about $6.2 \mathrm{~cm}^{2}\left(1 \mathrm{in.}{ }^{2}\right)$, and the other large coupon immersed in tap water revealed a small area of about $0.06 \mathrm{~cm}^{2}\left(0.01 \mathrm{in.}{ }^{2}\right)$ with light pitting. In both cases, the pitting was confined to a rolling plane surface. Only very light and sporadic "discoloration" was observed on any of the cut faces of these coupons.

Upon initial inspection of the coupons immersed in water, detection of the pits was facilitated by the rather voluminous white, gelatin-like corrosion product associated with the pits (as is typical of aluminum in water). (No corrosion product accumulation or other evidence of pitting was noted after eight days of exposure, and the coupons were not examined again until the end of test at 20 days exposure.) Some of the corrosion product was lightly adherent to the coupon and a significant fraction accumulated on top of the water immediately above the pit location. Bubbles of hydrogen, which is also a product of the oxidation process, were also observed trapped within the white corrosion product on the specimen and in the corrosion product floating on the water. No analytical determination was attempted, but given the water environment, the low temperature, and the "gel" consistency, the white corrosion product is almost certainly 
bayerite, denoted as $\mathrm{Al}(\mathrm{OH})_{3}$, or perhaps more properly written as $\mathrm{Al}_{2} \mathrm{O}_{3}{ }^{*} 3 \mathrm{H}_{2} \mathrm{O}$. Sometimes, the bayerite also contains signs of the contaminant species in water that contributed to pitting. Iron, copper, and chlorides are all common to tap water and each is commonly associated with pitting of aluminum in water, but identifying the specific cause of the pitting on 2519 aluminum is outside the scope of this work.

After the corrosion product was removed (light rinsing with water and/or light wiping removed the majority and an ultrasonic treatment in acetone finished the job effectively), some of the pitted areas appeared very slightly discolored (due at least in part to the destruction of an otherwise shiny surface). However, no pitting was readily detectable with the unaided eye. Microscopically, the density of the pits varied and they appeared to be crudely hemispherical. No analytical measurements of pit size have been attempted, but observation at about $50 X$ suggests the pits are generally on the order of $100 \mu \mathrm{m}$ (up to 4 mils) in diameter and $50 \mu \mathrm{m}$ (2 mils) deep. In a few locations, such pits are sufficiently close together that they appear as larger pits up to 250-375 $\mu \mathrm{m}$ (10-15 mils) across but still only 25-50 $\mu \mathrm{m}$ (1-2 mils) deep.

The smaller coupons (emphasizing the plate cross section as a cut surface) immersed in tap water revealed no cletectable pitting but did exhibit very light staining toward dark gray over substantial areas. The staining may represent a "thickened" oxide film that provides a different luster on the coupon surface.

In the galvanic couples between 6061 and 2519 aluminum specimens with tap water, very light, scattered pitting was detected via tiny corrosion product at the extreme edges of the large 2519 aluminum coupons. No similar corrosion was detected on the smaller coupons. The extent of pitting (number, density, and depth) was much less than that previously described for the coupons fully immersed in tap water. No attack of the 6061 aluminum was observed. The tap water that was originally between the respective coupons was no doubt largely displaced to the edges of the "sandwich" as the coupons (resting one on top of the other) came together. The displacement of the water to the coupon edges may account for the isolation of the pitting at this location. Without measurement of current flow between the dissimilar aluminum types, it is not possible to determine whether the observed corrosion along the specimen edges is a galvanic effect or simply represents superior resistance to tap water "immersion" for 6061 aluminum compared to 2519 aluminum. 
The microsol 165 appeared to be very benign toward the 2519 aluminum in all cases. In general, the microsol 165 tended to generate a rather slimy film that seemed to "encase" the specimens, and perhaps that contributed to the "protection" afforded the aluminum. 



\section{CONCLUSIONS AND RECOMMENDATIONS}

Extended exposures (three weeks) of prototypic 2519 aluminum in environments expected during fabrication of AAAV components indicate no corrosion problems are likely to be encountered by brief exposures to high humidity air, solvent 140 , and microsol 165 cutting fluid. Tap water exposures may be more problematic, as mild pitting was observed for several 2519 aluminum coupons exposed to the building tap water. However, pitting sufficient to be visible to the unaided eye required exposures in excess of eight days to develop in these tests, indicating tap water can be utilized if the duration of exposure is properly limited. Fundamentally, parts which require exposure to tap water should be cleaned/rinsed with water chaser (solvent 140) and dried as rapidly as practical, say, within 72 hours maximum, to avoid pitting.

Potentially, water of higher resistivity than building tap water might be less corrosive toward 2519 aluminum. If long term contact of water and the 2519 parts cannot be avoided, using water of at least $1 \mathrm{Mohm}-\mathrm{cm}$ resistivity as a way to prolong the time required for pit initiation should be considered.

For outdoor storage of aluminum, contact with water should be minimized. Practical recommendations include a cover for the material (roof, tarp, etc) that permits air circulation underneath. If the material were to become damp (rain water, condensate, etc), drying is desirable. Do not store the aluminum directly on the ground or on surfaces that leach corrosive substances (eg, wood, asphalt). Various plastic or treated-paper wraps should be utilized to the greatest extent possible.

Corrosion problems associated with galvanic couples between 6061 and 2519 aluminums were not significant over the duration of the test exposures discussed herein. However, care should be taken to limit dissimilar aluminum material contact during the fabrication process. Any interface between materials, even like materials, contains a crevice in which corrosion processes can be quite aggressive. Therefore, unless materials are "dry" they should be separated as often as practical to discourage galvanic and/or crevice corrosion problems. Using shims/sheets of plastic as an "insulator" to break contact between dissimliar metals may be useful. Even though the "dry" couple between steel and 2519 aluminum did not reveal any corrosion in this test, experience indicates that wet contact of steel and 2519 aluminum should be avoided. 
In addition, steel wire brushes for cleaning and scrubbing surfaces should be avoided as much as possible. In particular, particles of steel from the brushes can become embedded in the aluminum and likely will cause pitting and discoloration of exposed surfaces. This is not likely to be a problem for cleaning welds between passes, but steel brushes should be avoided for clean-up of the final weld pass.

Stainless steel brushes also embed particles that can cause pitting of aluminum in an "immersion" situation, but the particles themselves will not discolor or corrode in humid air. Therefore, stainless steel brushes are recommended for cleaning the aluminum welds (interpass and final pass clean-up), but the exposed surfaces of aluminum that have been cleaned with stainless steel brushes should be examined for embedded material or perhaps subsequently scrubbed with non-metallic scrub pads. (Examples of appropriate non-metallics might be materials referred to as "scotch pads" or "BearTex.") 


\section{ACKNOWLEDGEMENT}

Funding for these scouting tests was made available from G. W. Joe and prototypic aluminum specimens provided by $A$. A. Barnes. Document preparation was supported by F. C. Stooksbury. Constructive review of the manuscript was provided by D. F. Wilson and J. F. King. 



\section{INTERNAL DISTRIBUTION}

\author{
1. A. A. Barnes \\ 2. D. F. Craig \\ 3. J. R. DiStefano \\ 4. H. W. Hayden \\ 5-10. G.W. Joe \\ 11. J. F. King
}

12-15. S. J. Pawel

16. Central Research Library Document Reference Section

17-18. Laboratory Records Department-OSTI

19. Laboratory Records-RC 